Lepr. Rev. (1973) 44, 13-21

\title{
The Differential Tuberculin Test in Leprosy
}

\author{
M. R. M. PINTO, S. N. ARSECULERATNE and L. V. WELIANGA
}

Department of Bacteriology, University of Sri Lanka, Peradeniya, Sri Lanka

\begin{abstract}
The differential tuberculin test has been carried out on a group of leprosy patients using 5 different PPD antigens (S, Y, G, B and F) obtained from Mycobacterium tuberculosis and other mycobacterial species. The patterns of sensitization seen in the leprosy patients were found to be different from those of the general population and of tuberculous patients, but no marked differences in the patterns were seen between the patients with lepromatous and those with tuberculoid leprosy.

In both groups of patients, there was with all the antigens except PPD-F, a clear-cut group of non-reactors and a group of reactors. Both tuberculoid and lepromatous leprosy patients had, in contrast to tuberculous patients, a significant proportion of non-reactors. It was also found that the patterns of sensitization to antigens obtained from mycobacteria other than $M y c o$. leprae were not different in the two immunological extremes of leprous disease.
\end{abstract}

\section{Introduction}

Leprosy patients show two extremes of cell-mediated immunity (CMI). In the tuberculoid type of disease, CMI is said to be well developed, whereas in lepromatous leprosy the response is depressed (Almeida et al., 1970). Attempts at experimental sensitization of lepromatous patients with dinitrochlorobenzene revealed that the majority of them could not be sensitized by this method (Waldorf et al., 1966). On the other hand it has been shown that with the use of "stronger antigenic stimuli", such as keyhole limpet haemocyanin, it is possible to produce sensitization of these patients (Turk and Waters, 1969).

The immune deficiency in lepromatous leprosy has been shown to be specific to Myco. leprae. Thus, reviewing the work on the delayed-type response elicited by tuberculin-type sensitins, Hart and Rees (1967) concluded that species of mycobacteria other than Myco. leprae were capable of eliciting "positive" skin responses, irrespective of the clinical type of leprosy. They also deduced that "in spite of the common antigens shared by all species of mycobacteria, the characteristic anergy to lepromin in patients with lepromatous disease applies to no species of Mycobacterium other than to Myco. leprae." It has been shown that in a given area the prevalence of tuberculin positivity in leprosy patients is similar to that in healthy persons, but tuberculin reactivity is said to be significantly weaker in lepromatous patients than in tuberculoid patients in the same age group and from the same area.

The Ceylonese have been shown to possess a high level of sensitization to mycobacterial PPDs (Pinto et al., 1972). At least in some rural areas in the lowlands of Sri Lanka, up to $98 \%$ of the general population show reactions of 
$2 \mathrm{~mm}$ or more on tuberculin testing with PPD sensitins from various mycobacteria, indicating some degree of sensitization to mycobacterial antigens.

The present investigation is an attempt to study the reaction of leprosy patients in Sri Lanka to various mycobacterial PPD sensitins.

\section{Materials and Methods}

The patients studied in this survey (total 153) were those being treated for leprosy, either as out-patients at peripheral clinics or as in-patients at Institutions of the Anti-Leprosy Campaign of Sri Lanka. The diagnosis of the clinical type of leprosy was as made by the Campaign. Only patients considered to have active disease requiring treatment were tested.

The characteristics of the populations tested are summarized in Tables 1, 2, and 3. The majority of subjects investigated were patients who had been receiving treatment for longer periods of time. Also the majority of patients tested in this study had lepromatous disease, but the proportions of patients investigated do

TABLE 1

Percentage distribution of patients (total 153) according to source

\begin{tabular}{lrrr}
\hline & \multicolumn{2}{c}{ Type of disease } & Total \\
& Tuberculoid & Lepromatous & \\
\hline Hendala Hospital (in-patients) & 24 & 24 & 48 \\
Mantivu Hospital (in-patients) & 7 & 31 & 38 \\
Gampola Clinic (out-patients) & 5 & 5 & 10 \\
Katugastota Clinic (out-patients) & 4 & 0 & 4 \\
Total & 40 & 60 & 100 \\
\hline
\end{tabular}

TABLE 2

Percentage distribution of leprosy patients according to type of leprosy and duration of disease

\begin{tabular}{lcccc}
\hline & \multicolumn{4}{c}{ Duration of disease (years) } \\
Type of disease & $<2$ & $2-5$ & $5-10$ & $>10$ \\
\hline Tuberculoid & 10 & 6 & 12 & 12 \\
Lepromatous & 5 & 15 & 18 & 22 \\
Total & 15 & 21 & 30 & 34 \\
\hline
\end{tabular}

TABLE 3

Percentage distribution of tuberculoid and lepromatous leprosy patients according to age and sex

\begin{tabular}{|c|c|c|c|c|c|c|}
\hline \multirow{2}{*}{ Age (years) } & \multicolumn{3}{|c|}{ Tuberculoid } & \multicolumn{3}{|c|}{ Lepromatous } \\
\hline & Male & Female & Total & Male & Female & Total \\
\hline$<24$ & 3 & 2 & 5 & 1 & 1 & 2 \\
\hline $25-34$ & 3 & 1 & 4 & 8 & 1 & 9 \\
\hline $35-44$ & 5 & 2 & 7 & 12 & 1 & 13 \\
\hline$>45$ & 19 & 5 & 24 & 32 & 4 & 36 \\
\hline Total & 30 & 10 & 40 & 53 & 7 & 60 \\
\hline
\end{tabular}


not reflect the real distribution of the types of leprosy in the country as a whole, where in newly diagnosed cases tuberculoid disease is four times commoner than lepromatous leprosy (Department of Health Services, 1972). The antigens used in this survey (kindly supplied by Dr Lydia B. Edwards of the U.S. Public Health Service) were as follows:

PPD-S from Myco. tuberculosis; PPD-Y from Myco. kansasii (Runyon's Group I); PPD-G from Gause strain Scotochromogen (Runyon's Group II); PPD-B from Myco. batteyi (Runyon's Group III); PPD-F from Myco. fortuitum (Runyon's Group IV).

The test protocol followed was essentially the same as that described in a study of differential tuberculin sensitivity in rural populations in Sri Lanka reported earlier (Pinto et al., 1972). Every subject was given 2 antigens on the volar aspect of either forearm, each antigen being administered in a dose of $0.1 \mathrm{ml}$ (equivalent to $5 \mathrm{TU}$ ) intradermally, using the technique recommended by the World Health Organization (1963). Every subject was given PPD-S, and 3 other antigens when permitted. The reactions were read as the maximum palpable transverse induration, 48 to 72 hours after injection. All antigens were administered and results read throughout the study by the same person.

\section{Results}

The frequency distributions of the reactions to the different antigens in the entire group of leprosy patients tested is shown in Figs la to le. The majority of the patients tested (more than $80 \%$ ) came from the lowland coastal areas of Sri Lanka and hence the frequency distributions of the reactions to the same antigen from lowland Sri Lanka (Pinto et al., 1972) are also presented in the same figure, together with the distribution of reactions seen in tuberculosis patients in the country (Pinto et al., 1973). The distributions of reactions to the different antigens in the two clinical types of disease are shown in Figs $2 \mathrm{a}$ to $2 \mathrm{e}$.

\section{DISTRIBUTION OF REACTIONS TO INDIVIDUAL ANTIGENS}

$P P D-S$. The distribution of reactions to this antigen in the entire group as well as in the separate tuberculoid and lepromatous groups is clearly bimodal. The right-hand component of the curve consists of a well-marked reactor group with a mode at 14 to $15 \mathrm{~mm}$ and closely resembles the frequency distribution seen in tuberculosis patients for whom this antigen is the homologous one. There appears to be no difference in the distribution of reactions between patients with the tuberculoid and lepromatous forms of leprosy.

$P P D-Y$. With this antigen, the distribution obtained from the entire group of leprosy patients (Fig. Ib) does not present as distinct a bimodal appearance as does the distribution of PPD-S, but a demarcation can still be made out. Here too the right-hand reactor component appears to resemble the distribution of the reactor component for this antigen, seen in tuberculous patients with similar modes. As with PPD-S a much greater proportion of non-reactors are seen in leprosy patients than in tuberculous patients. The distribution shown by the patients with tuberculoid leprosy seems to have a reactor component with a mode of 12 to $13 \mathrm{~mm}$, larger than that of lepromatous patients (6 to $9 \mathrm{~mm}$. Fig. $2 \mathrm{~b}$ ). 

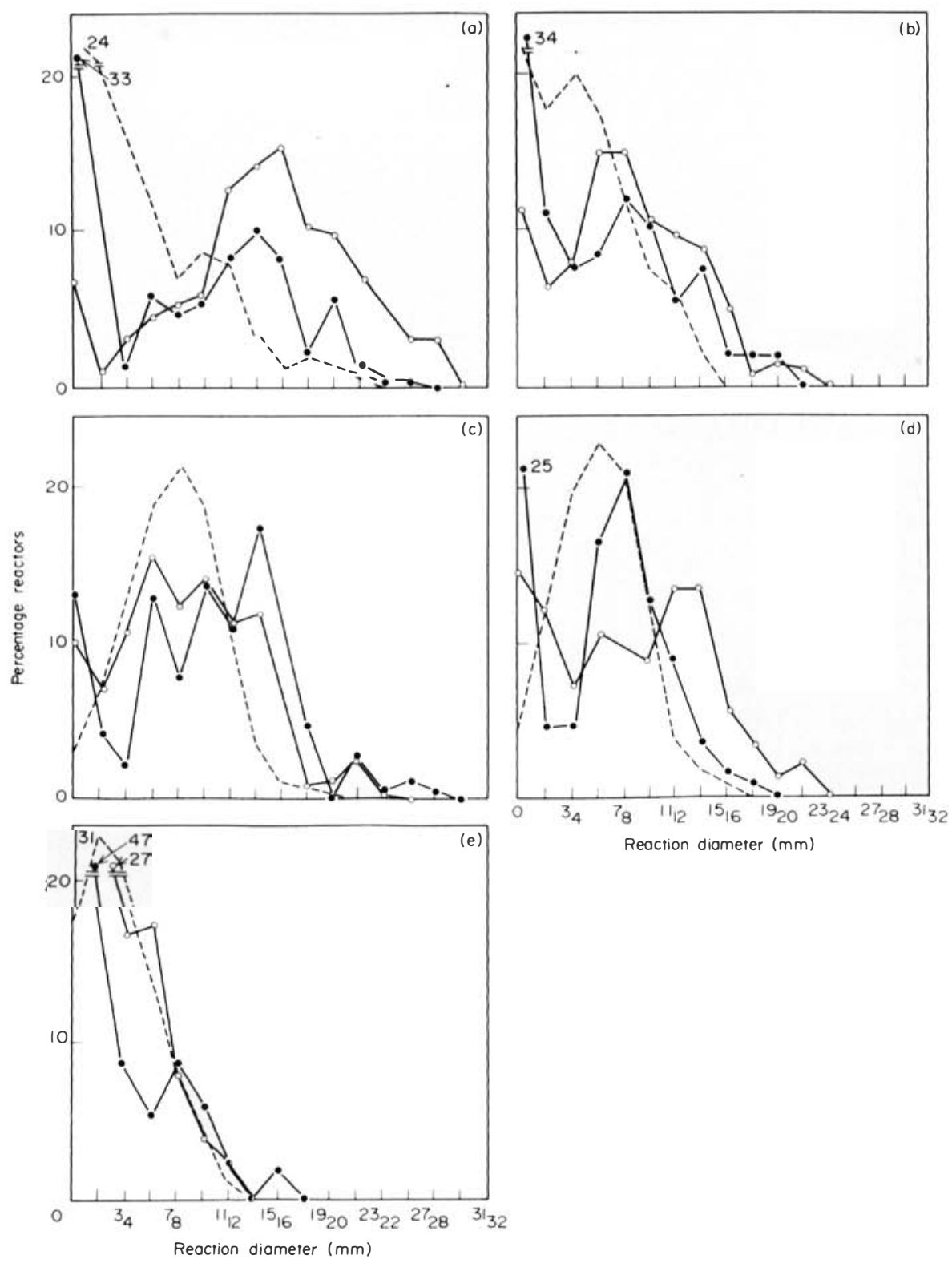

Fig. 1. Frequency distribution of reaction diameters in leprosy patients $(-\bullet-)$, tuberculous patients $(-\infty-)$ ) and normal persons $(---) ; \mathrm{a}=$ PPD-S, $\mathrm{b}=$ PPD-Y, $\mathrm{c}=$ PPD-G, $\mathrm{d}=$ PPD-B and $\mathrm{e}=$ PPD-F. 

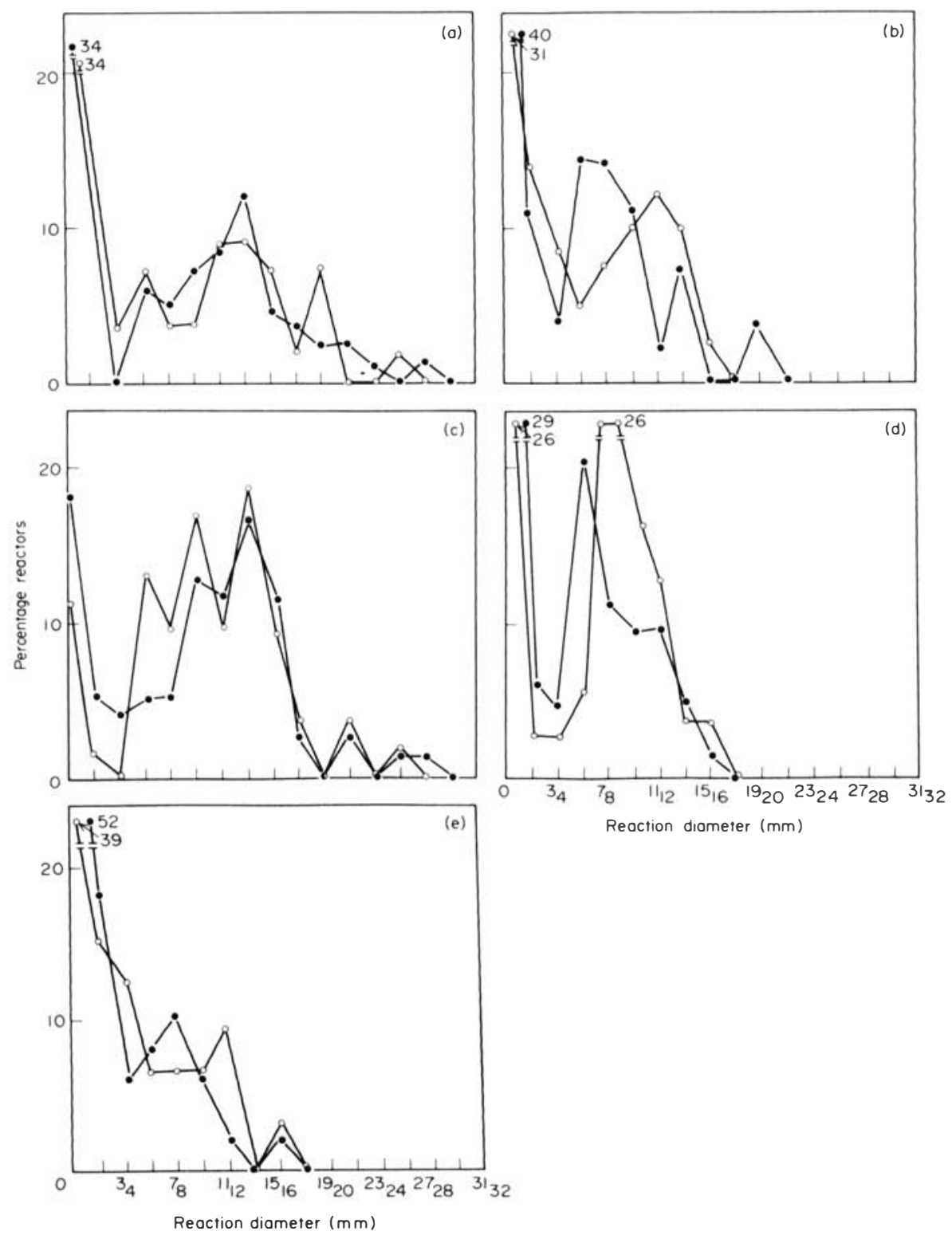

Fig. 2. Frequency distribution of reaction diameters in lepromatous patients $(-\bullet-)$ and tuberculoid patients $(-\infty-) ; \mathrm{a}=$ PPD-S, $\mathrm{b}=$ PPD-Y, $\mathrm{c}=$ PPD-G, $\mathrm{d}=$ PPD-B and $\mathrm{e}=$ PPD-F. 
$P P D-G$. The frequency distribution to this antigen also appears to show a bimodal pattern. The identification of a clear cut mode of reactors is more difficult, but the latter mode seems to be larger than that of either tuberculous patients or of the general population presented for comparison (Fig. lc). The distribution of tuberculoid and lepromatous patients also appear to be similar (Fig. 2c).

$P P D-B$. The separation of reactions into a reactor component and non-reactors is marked. The tuberculoid patients appear to show a larger mode (10 to $11 \mathrm{~mm}$ ) than lepromatous patients ( 6 to $7 \mathrm{~mm}$, Fig. $2 \mathrm{~d}$ ).

$P P D-F$. The separation of reactions into non-reactors and reactors is not clear. The distribution of reactions in the two types of disease appears similar (Fig. 2e).

The mean reaction sizes to the different antigens in leprosy patients, tuberculous patients, and the general population are presented as sensitivity profiles (Edwards, Hopwood and Palmer, 1965) in Fig. 3a. The profiles of the two types of leprosy patients are shown in Fig. 3b. There appears to be no difference between the profiles of the tuberculoid and those of lepromatous patients.

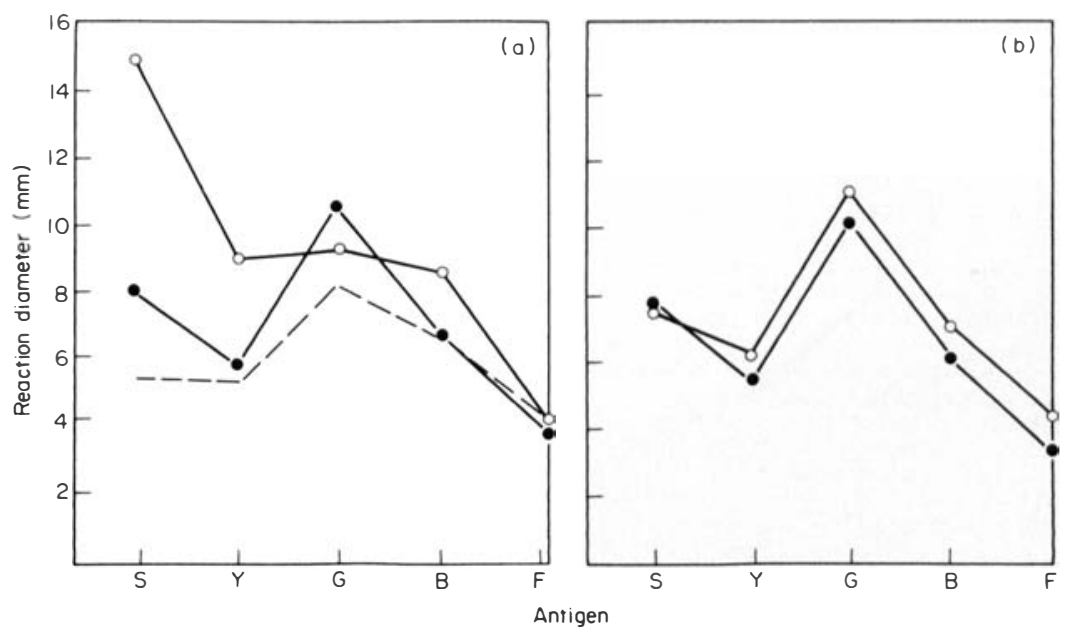

Fig. 3. a, Sensitivity profile of leprous (- - $)$, tuberculous $(-\circ-)$, and normal persons $(---)$ to 5 mycobacterial PPDs. b, Sensitivity profile of lepromatous leprosy $(-\bullet-)$ and tuberculoid leprosy patients (-O-) to 5 mycobacterial PPDs.

Clinically, it is a common practice to classify tuberculin reactions as "positive" or "negative"-positive being considered to indicate infection by the homologous organism. At different times varying criteria of "positive" have been proposed. In Table 6 is presented the percentage of positive reactors among the two clinical groups of leprosy patients as compared with tuberculosis patients and the general population from rural, lowland Sri Lanka.

\section{Discussion}

It has been said that the "evaluation of delayed hypersensitivity in leprosy has been hampered in the past by the use of antigens to which the incidence of 
TABLE 4

Percentage distribution of non-reactors $(0-1 \mathrm{~mm})$ in leprosy and tuberculous patients

\begin{tabular}{lcccc}
\hline Disease & $\begin{array}{c}\text { All } 4 \\
\text { antigens }\end{array}$ & $\begin{array}{c}\text { 3 out of } 4 \\
\text { antigens }\end{array}$ & $\begin{array}{c}\text { 2 out of } 4 \\
\text { antigens }\end{array}$ & $\begin{array}{c}1 \text { out of } 4 \\
\text { antigens }\end{array}$ \\
$\begin{array}{l}\text { Lepromatous leprosy } \\
\text { Tuberculoid leprosy }\end{array}$ & 6 & 4 & 10 & 15 \\
Tuberculosis patients & 2 & 2 & 10 & 10 \\
General population, lowland Sri Lanka & 2 & 3 & 7 & 19 \\
\hline
\end{tabular}

TABLE 5

Percentage distribution of reaction size according to antigen and type of leprosy

\begin{tabular}{|c|c|c|c|c|c|c|c|c|c|c|}
\hline \multirow{2}{*}{$\begin{array}{l}\text { Reaction } \\
\text { size }\end{array}$} & \multicolumn{2}{|c|}{$\mathrm{S}$} & \multicolumn{2}{|c|}{$\mathrm{Y}$} & \multicolumn{4}{|c|}{ Antigen } & \multicolumn{2}{|c|}{$\mathrm{F}$} \\
\hline & $\mathrm{T}^{a}$ & $L^{b}$ & $\mathrm{~T}$ & $\mathrm{~L}$ & $\mathrm{~T}$ & $\mathrm{~L}$ & $\mathrm{~T}$ & $\mathrm{~L}$ & $\mathrm{~T}$ & $\mathrm{~L}$ \\
\hline $0-1 \mathrm{~mm}$ & 34 & 34 & 31 & 40 & 11 & 18 & 26 & 29 & 39 & 52 \\
\hline$>2 \mathrm{~mm}$ & 66 & 66 & 69 & 60 & 89 & 82 & 74 & 71 & 61 & 48 \\
\hline$>6 \mathrm{~mm}$ & 50 & 54 & 46 & 46 & 89 & 73 & 69 & 60 & 30 & 24 \\
\hline$>10 \mathrm{~mm}$ & 40 & 44 & 34 & 22 & 67 & 61 & 38 & 25 & 18 & 10 \\
\hline
\end{tabular}

${ }^{a} \mathrm{~T}$, tuberculoid leprosy.

${ }^{b} \mathrm{~L}$, lepromatous leprosy.

TABLE 6

Percentage distribution of leprosy patients according to type of leprosy and duration of disease

\begin{tabular}{lrccc}
\hline & \multicolumn{4}{c}{ Duration of disease (years) } \\
Type of disease & $<2$ & $2-5$ & $5-10$ & $>10$ \\
\hline Tuberculoid & 10 & 6 & 12 & 12 \\
Lepromatous & 5 & 15 & 18 & 22 \\
$\quad$ Total & 15 & 21 & 30 & 34 \\
\hline
\end{tabular}

sensitization is not clearly defined in healthy or comparable controls" (Waldorf et al., 1966). Thus the literature on the tuberculin test in leprosy appears to be conflicting. Wade (1950) found tuberculin reactivity to be diminished in lepromatous leprosy. In contrast, Lowe and McNulty (1953) and Lowe (1955) concluded that the clinical characteristics of leprosy did not influence the response to tuberculin. On the other hand, Bullock (1966) found a decreased incidence of skin reactions in certain patients with either the tuberculoid or lepromatous form of the disease. The evidence from this study seems to be more in agreement with the findings of Bullock. From the frequency distributions it is apparent that no single antigen used in this study could discriminate between the two types of leprous disease, since a high incidence of non-reactors is seen to each antigen in both groups of patients. With all antigens except PPD-F, it is seen that the frequency distributions in the leprosy patients are more or less different from those of tuberculosis patients and the general population. This suggests that the immunological status of leprosy patients with reference to cell-mediated 
immunity is one that is different from that of the latter two groups. However, this pattern appears to be different in regard to the humoral antibody response, which is marked in lepromatous leprosy (Almeida et al., 1970) whereas in tuberculoid leprosy the high levels of antibody seen in the former are not found. It has been shown that lepromatous leprosy patients show antibody titres of almost the same order as tuberculous patients, as detected by Takahashi's antitubercle phosphatide kaolin agglutination test (Takahashi, 1962) while patients with tuberculoid leprosy show a distribution of titres similar to that seen in "normal" blood donors (Pinto et al., unpublished data, 1972). This finding, and the similarity of the reactor components of reactions to PPD-S in leprosy patients, suggests a close antigenic (phosphatide and protein) relationship of $M y c o$. leprae to $M y c o$. tuberculosis.

It is now generally accepted that some form of immunological deficit exists in lepromatous leprosy as far as cellular responses are concerned. But some workers believe that this immune depression is specific for the antigens of Myco. leprae, while others conclude that the depression is non-specific. Evidence has been produced that showed that following BCG vaccination, tuberculin conversion rates were much lower in children of leprosy patients as compared with those of parents without leprosy (Jamison and Vollum, 1968). This suggests that genetic factors may possibly be involved in the ability of subjects to respond to antigens which evoke delayed hypersensitivity responses.

\section{Acknowledgements}

We are grateful to Dr Lydia B. Edwards of the U.S. Public Health Service for her gift of PPD antigens used in this study. We thank Dr P. J. de Fonseka, Superintendent of the Anti-leprosy Campaign in Ceylon, for permission to carry out the studies in hospitals and clinics of the campaign; Dr G. S. Arudpragasam, Dr Adolphus Silva and Dr M. Arumunayagam (Medical Officers of the Campaign's Hospitals) for assistance and Messrs D. M. Hemawardene and J. W. Premadasa for clerical help.

\section{References}

Almeida, J. O. et al. (1970). Immunological problems in leprosy research. Bull. Wld Hlth Org. 43, 879 .

Bullock, W. E. (1966). Quoted by Waldorf et al. (1966).

Department of Health Services (1972). Epidemiological Bulletin No. 47. Colombo, Ceylon.

Edwards, L. B., Hopwood, L. and Palmer, C. E. (1965). Identification of mycobacterial infections. Bull. Wld Hlth Org. 33, 405.

Hart, P. D'Arcy and Rees, R. J. W. (1967). Lepromin and Kveim antigen reactivity in man and their relation to tuberculin reactivity. Brit. med. Bull. 23, 80 .

Jamison, D. C. and Vollum, R. L. (1968). Tuberculin conversion in leprous families in Northern Nigeria. Lancet ii, 1271.

Lowe, J. (1955). Quoted by Waldorf et al. (1966).

Lowe, J. and McNulty, F. (1953). Tuberculosis and leprosy. Immunological studies. Lepr. Rev. 24,61 .

Pinto, M. R. M., Arsecularatne, S. N., Uragoda, C. G. and Hemawardene, D. M. (1972). Differential tuberculin testing in rural populations in Ceylon. Tubercle (Lond.) 53, 182.

Pinto, M. R. M., Arseculeratne, S. N., Uragoda, C. G. and Hemawardene, D. M. (1973, in press). The differential tuberculin test in tuberculosis patients in Ceylon. Tubercle (Lond.) 54.

Takahashi, Y. (1962). Specific serum agglutination of kaolin particles sensitized with tubercle phosphatide and its clinical evaluation as a serodiagnostic test for tuberculosis. Am. Rev. resp. Dis. 85, 708. 
Turk, J. L. and Waters, M. F. R. (1969). Cell-mediated immunity in patients with leprosy. Lancet ii, 243.

Wade, H. W. (1950). Quoted by Waldorf et al. (1966).

Waldorf, D. S., Sheagren, J. N., Trautman; J. R. and Block, J. B. (1966). Impaired delayed hypersensitivity in patients with lepromatous leprosy. Lancet ii, 773. 